\title{
Time to invasive treatment of patients with non-ST elevation myocardial infarction
}

\section{OInes Vinković*, CMihajlo Kovačić}

Čakovec County Hospital, Čakovec, Croatia

\begin{abstract}
KEYWORDS: acute coronary syndrome, non ST elevation myocardial infarction, invasive treatment. CITATION: Cardiol Croat. 2021;16(1-2):9. | https://doi.org/10.15836/ccar2021.9
\end{abstract}

*ADDRESS FOR CORRESPONDENCE: Ines Vinković, Županijska bolnica Čakovec, I.G.Kovačića 1e, HR-42000 Čakovec, Croatia. / Phone: +385-91-8905037 / E-mail: iness.vinkovic@gmail.com

ORCID: Ines Vinković, https://orcid.org/0000-0003-1705-8295 • Mihajlo Kovačić, https://orcid.org/0000-0002-2577-9474
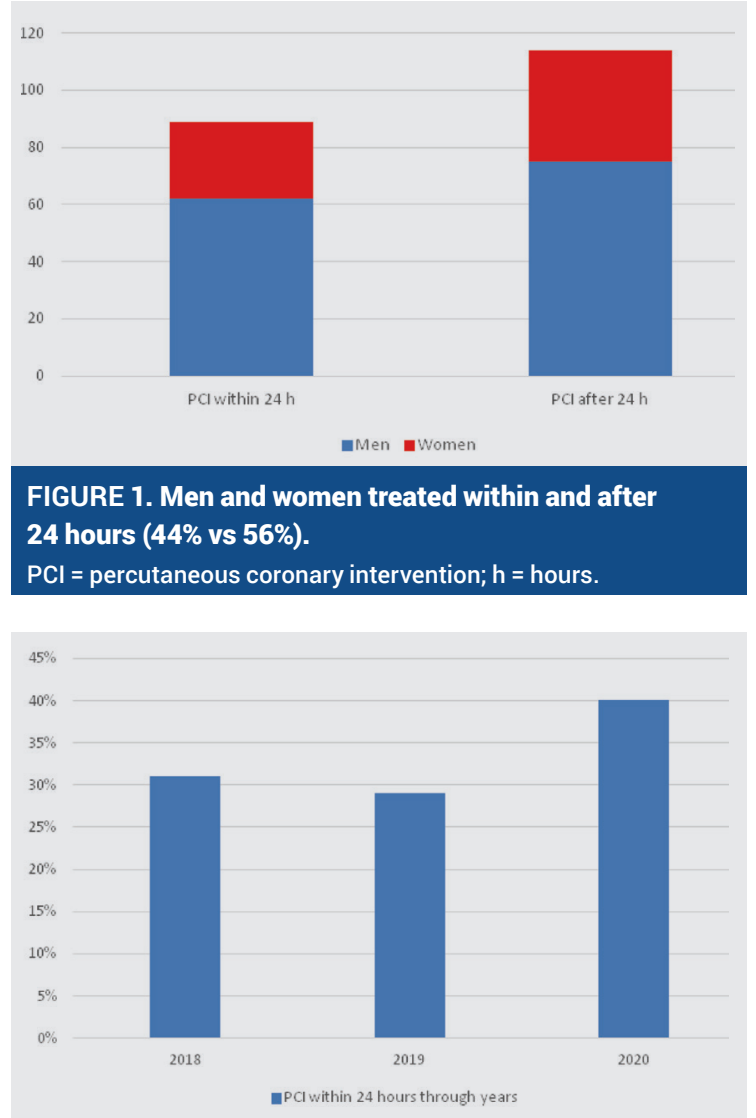

FIGURE 2. Number of patients treated within 24 hours through years.

$\mathrm{PCl}=$ percutaneous coronary intervention.
Background: According to the latest European Society of Cardiology (ESC) guidelines for patients with non ST elevation myocardial infarction (NSTEMI), the time to invasive treatment is divided into an immediate invasive strategy within two hours for very high-risk patients, an early invasive strategy within 24 hours for high-risk patients, and a selective invasive strategy within 72 hours for low-risk patients, although the time interval that is most optimal for high-risk patients has not yet been determined ${ }^{1}$. Our goal was to examine in what time interval patients were treated in County Hospital Čakovec after acute coronary syndrome (ACS) - NSTEMI in the previous 3 years.

Patients and Methods: Included were patients with ACS - NSTEMI from January 2018 to November 2020. The time of the first contact with the medical staff and the time of the beginning of the invasive treatment was recorded, then the time interval was calculated.

Results: Total number of included NSTEMI patients was 203, patients with incomplete documentation were excluded. There were 137 (67\%) men and 66 (33\%) women, median age was 67 years, women were older than men (71 vs 63 years). 118 (58\%) patients were from primary PCI (percutaneous coronary intervention) centre and 85 (42\%) patients were from local hospitals. 89 patients (44\%) were treated within 24 hours, while 149 patients $(73 \%)$ were treated within 72 hours. Patients treated within 24 hours were younger than those treated after 24 hours (62 vs 70 years), women were treated at a slightly lower percentage within the first 24 hours compared to men (41\% vs $45 \%$ ), (Figure 1). More patients were treated within 24 hours from the primary PCI center than from local hospitals (60\% vs $23 \%$ ). Over the past three years, there has been an increase in the number of patients treated within 24 hours, 31\% of patients during 2018, 29\% during 2019, while this year, the percentage was 40\% (Figure 2)

Conclusion: A large number of patients diagnosed with NSTEMI are at high risk, and only one in ten receives an invasive treatment strategy within the recommended timeframe ${ }^{2}$. Our goal is to treat as many patients as possible within the first 24 hours.

\section{RECEIVED:}

December 8, 2020

ACCEPTED:

December 18, 2020

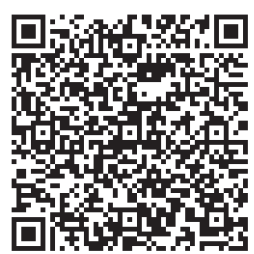

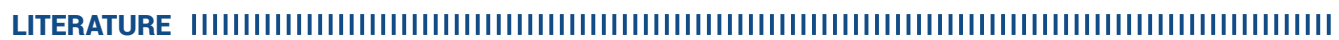

1. Collet JP, Thiele H, Barbato E, Barthélémy 0, Bauersachs J, Bhatt DL, et al; ESC Scientific Document Group. 2020 ESC Guidelines for the management of acute coronary syndromes in patients presenting without persistent ST-segment elevation. Eur Heart J. 2020 Aug 29:ehaa575. https://doi.org/10.1093/eurheartj/ehaa575

2. Rashid M, Curzen N, Kinnaird T, Lawson CA, Myint PK, Kontopantelis E, et al. Baseline risk, timing of invasive strategy and guideline compliance in NSTEMI: Nationwide analysis from MINAP. Int J Cardiol. 2020 Feb 15;301:7-13. https://doi.org/10.1016/j.ijcard.2019.11.146 